\title{
Improved flame retardant of intumescent flame retardant flame-retarded high density polyethylene with fullerene decorated by iron compound
}

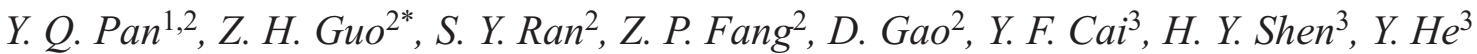 \\ ${ }^{1}$ MOE Key Laboratory of Macromolecular Synthesis and Functionalization, Institute of Polymer Composites, Zhejiang \\ University, 310027 Hangzhou, PR China \\ ${ }^{2}$ Laboratory of Polymer Materials and Engineering, Ningbo Institute of Technology, Zhejiang University, 315100 \\ Ningbo, PR China \\ ${ }^{3}$ Gongniu Group Co., Ltd, Guanhaiwei Industrial Area, Cixi, 315314 Zhejiang Province, PR China
}

Received 20 February 2019; accepted in revised form 30 April 2019

\begin{abstract}
Fullerene decorated by iron compound $\left(\mathrm{C}_{60}-\mathrm{Fe}\right)$ was fabricated via solution reaction and characterized by $\mathrm{X}$-ray photoelectron spectra and wide-angle X-ray diffraction. By a partial replacement of intumescent flame retardant (IFR) in flame retarded polyethylene ( $\mathrm{PE}$ ) by $\mathrm{C}_{60}-\mathrm{Fe}$, the flame retardant properties of $\mathrm{PE} / \mathrm{IFR}$ composites were increased dramatically. When $2 \mathrm{wt} \%$ IFR was substituted by $\mathrm{C}_{60}-\mathrm{Fe}$, a compact and continuous char barrier was formed, resulting in the reduction of the peak of heat release rate $(P H R R)$ and the total heat released $(T H R)$. Also, the ignition time $\left(t_{\text {ign }}\right)$ prolonged form 67 to $114 \mathrm{~s}$ and the time to $P H R R$ ( $t_{\mathrm{PHRR}}$ ) prolonged form 208 to $455 \mathrm{~s}$. The improvement on flame retardancy of PE/IFR/ $\mathrm{C}_{60}-\mathrm{Fe}$ composites was due to the synergistic influence between the catalytic charring ability of $\mathrm{Fe}$ and the free radical trapping effect of $\mathrm{C}_{60}$.
\end{abstract}

Keywords: nanocomposites, fullerene, metallic compound, intumescent flame retardant, catalytic charring

\section{Introduction}

As thermal degradation and combustion mechanisms of polyethylene (PE) are free radical chain reactions, a large number of highly active free radicals will be produced when heated or ignited. These free radicals will accelerate the degradation and combustion process. Therefore, cutting off free radical chain reaction can inhibit the degradation and combustion process. For example, rare earth compounds [1, 2], graphene [3] and hindered amines [4-6] were added to polyolefin to capture the free radicals and terminate the chain reaction.

Fullerene $\left(\mathrm{C}_{60}\right)$ also has positive effects on the thermal stability and flame retardancy of polymers due to its free radical trapping ability. Previous studies of our group [7-12] had found that $\mathrm{C}_{60}$ could effectively improve the thermal stability of polymers degraded by free-radical mode, especially at the initial stage of degradation. Moreover, when $\mathrm{C}_{60}$ was combined with brominated flame retardants (BFRs) or aluminum hydroxide (ATH), the flame retardant properties of composites enhanced [13-15]. For BFRs $/ \mathrm{C}_{60}$ system, $\mathrm{C}_{60}$ trapped the alkyl radicals, chain radicals and bromine radicals in condensed phase to terminate the thermal degradation of polymer and reduce the volatile gases. Meanwhile, BFRs also trapped alkyl radicals and chain radicals, so the final performances of $\mathrm{BFRs} / \mathrm{C}_{60}$ system were decided by the ratio of $\mathrm{C}_{60}$ and BFRs contents. The synergistic effect between $\mathrm{C}_{60}$ and $\mathrm{ATH}$ was different 
from that observed between $\mathrm{C}_{60}$ and BFRs. $\mathrm{As}_{60}$ cooperated with $\mathrm{ATH}$, the protecting layer hindered the release of free radicals, allowing $\mathrm{C}_{60}$ to have more time to capture free radicals and making the matrix more difficult to burn. However, the integrated flame retardant effect of $\mathrm{C}_{60}$ and intumescent flame retardant (IFR) was not satisfactory. Although the ignition time was slightly prolonged (due to the free radical scavenging effect of $\mathrm{C}_{60}$ ), the peak of heat release rate and the total heat released both increased, which was caused by the thermal conductivity of $\mathrm{C}_{60}$ [16] and the non-continuous char layer.

For intumescent flame retardant system, the continuity and compactness of the char formed in the combustion process is directly related to the flame retardant performance of materials. As common flame retardant synergists, metal compounds can promote the formation of continuous protective char. As reported, metal oxide [17-20], metal chlorides [21], metal chelates [22] and metal phosphates [22, 23] exhibited good efficiency in improving flame retardancy of polymers, such as polypropylene (PP), polyamide (PA), epoxide resin (EP) and acrylonitrile butadiene styrene (ABS), by catalyzing the formation of stable char during combustion. $\mathrm{Ni}, \mathrm{Mn}, \mathrm{Cu}, \mathrm{Fe}, \mathrm{Zn}$, etc, are the commonly used metals in which $\mathrm{Fe}$ is a good choice for char-forming catalyst agent [24-28]. Iron compounds could improve the char structure and enhance the flame retardant performance of composites [26].

In this work, fullerene decorated by iron compound $\left(\mathrm{C}_{60}-\mathrm{Fe}\right)$ was fabricated and used combined with IFR to investigate their flame retardant effects on polyethylene (PE).

\section{Experimental details}

\subsection{Materials}

High-density polyethylene (HDPE, code 5000S, MFR $=0.9 \mathrm{~g} / 10 \mathrm{~min}$ ) was purchased from Yangzi Petrochemical Co., Ltd., Nanjing, China. $\mathrm{C}_{60}$ (purity: $>99.9 \%$ ) was purchased from Puyang Yongxin Co., Ltd., Henan, China. Ferric chloride hexahydrate $\left(\mathrm{FeCl}_{3} \cdot 6 \mathrm{H}_{2} \mathrm{O}, \mathrm{AR}\right)$ was purchased from Aladdin Reagent Co., Ltd., Shanghai, China. Xylene was purchased from Sinopharm Chemical Reagent Co., Ltd., China. Ammonium polyphosphate (APP) was purchased from Hangzhou JLS Flame Retardants Chemical Co., Ltd., China. Pentaerythritol (PER) was purchased from Aladdin Industrial Co., Ltd., China.

\subsection{Preparation of $\mathrm{C}_{60}-\mathrm{Fe}$}

$\mathrm{C}_{60}-\mathrm{Fe}$ was synthesized via a simple solution reaction. In a typical procedure, $0.5 \mathrm{~g} \mathrm{C}_{60}$ was dissolved in $150 \mathrm{ml}$ xylene, then $5 \mathrm{~g} \mathrm{FeCl}_{3} \cdot 6 \mathrm{H}_{2} \mathrm{O}$ was added into the above solution under magnetic stirring. The solution was refluxed at $85^{\circ} \mathrm{C}$ for $24 \mathrm{~h}$. Thereafter, the supernatant was obtained by centrifuging, followed by rotary evaporation under $75^{\circ} \mathrm{C}$ to remove the solvent. The final product was washed by alcohol-water for three times and dried at $80^{\circ} \mathrm{C}$ under a vacuum for $12 \mathrm{~h}$ and designated as $\mathrm{C}_{60}-\mathrm{Fe}$.

\subsection{Preparation of composites}

All samples were prepared via melt blending at $180^{\circ} \mathrm{C}$ in a torque rheometer (Thermohaake Rheomixer 600, Germany) with a rotor speed of $60 \mathrm{rpm}$ for 8 minutes. The ratio of APP/PER (abbreviated as IFR) was fixed as $3 / 1$ by weight, and the formulations were given in Table 1 . The mixed materials were then transferred to a mould and preheated at $180^{\circ} \mathrm{C}$ for $10 \mathrm{~min}$ utes, then pressed at $15 \mathrm{MPa}$ for 5 minutes followed by cool pressing for 5 minutes.

\subsection{Characterization}

Cone calorimetric tests were performed following the procedures indicated in the ISO 5660-1 standard, with Stanton Redcroft Cone Calorimeter (FTT, UK). The samples $\left(100 \times 100 \times 3 \mathrm{~mm}^{3}\right)$ were irradiated with a heat flux of $35 \mathrm{~kW} / \mathrm{m}^{2}$.

$\mathrm{X}$-ray photoelectron spectra (XPS) analysis was performed using a Thermo VG Scientific ESCALAB 250 spectrometer (UK).

The wide-angle X-ray diffraction (XRD) patterns were obtained using a X'Pert PROMPD diffraction system (PANalytical, Netherlands) with $\mathrm{Cu} \mathrm{K} \alpha$ radiation $(\lambda=1.542 \AA)$.

Transmission electron microscopy (TEM) observations were conducted on a JEM-1200EX electron microscope (JEOL, Japan) with an accelerating voltage of $120 \mathrm{kV}$.

Table 1. Formulations for PE composites.

\begin{tabular}{|l|c|c|c|c|}
\hline \multicolumn{1}{|c|}{ Sample code } & $\begin{array}{c}\text { HDPE } \\
{[\mathbf{w t} \%]}\end{array}$ & $\begin{array}{c}\text { IFR } \\
{[\mathbf{w t} \%]}\end{array}$ & $\begin{array}{c}\mathbf{C}_{\mathbf{6 0}}-\mathbf{F e} \\
{[\mathbf{w t} \% \mathbf{]}}\end{array}$ & $\begin{array}{c}\mathbf{C}_{\mathbf{6 0}} \\
{[\mathbf{w t} \% \mathbf{0}]}\end{array}$ \\
\hline $\mathrm{PE} / 15 \mathrm{IFR}$ & 85 & 15 & - & - \\
\hline $\mathrm{PE} / 14 \mathrm{IFR} / 1 \mathrm{C}_{60}-\mathrm{Fe}$ & 85 & 14 & 1 & - \\
\hline $\mathrm{PE} / 13 \mathrm{IFR} / 2 \mathrm{C}_{60}-\mathrm{Fe}$ & 85 & 13 & 2 & - \\
\hline $\mathrm{PE} / 12 \mathrm{IFR} / 3 \mathrm{C}_{60}-\mathrm{Fe}$ & 85 & 12 & 3 & - \\
\hline $\mathrm{PE} / 13 \mathrm{IFR} / 2 \mathrm{C}_{60}$ & 85 & 13 & - & 2 \\
\hline
\end{tabular}


Raman spectra with an excitation line of $541.5 \mathrm{~nm}$ were recorded with confocal Raman microscope (Jobin Yvon, France).

Scanning electron micrographs (SEM) were obtained with a Gemini 300 electron microscope (NEISS, German).

\section{Results and discussion}

\subsection{Characterization of $\mathrm{C}_{60}-\mathrm{Fe}$}

To clarify the structure of $\mathrm{C}_{60}-\mathrm{Fe}$, XPS and XRD were employed. Figure 1 presented the XPS and XRD spectra of $\mathrm{C}_{60}$ and $\mathrm{C}_{60}-\mathrm{Fe}$. Comparing with $\mathrm{C}_{60}$, the $\mathrm{Fe} 2 p$ peak at $711.7 \mathrm{eV}$ and $\mathrm{Cl} 2 p$ peak at $198.4 \mathrm{eV}$ were observed obviously in the survey spectrum of $\mathrm{C}_{60}-\mathrm{Fe}$. And the content of oxygen increased from 3.32 to $17.55 \%$. In $C 1 s$ spectrum of $\mathrm{C}_{60}$, four different chemical shifts appeared, which could be denoted as graphitic $s p 2 \mathrm{C}=\mathrm{C} / \mathrm{C}-\mathrm{C}$ at $284.4 \mathrm{eV}$, ether groups $(\mathrm{C}-\mathrm{O})$ at $286.2 \mathrm{eV}$, carbonyl groups $(\mathrm{C}=\mathrm{O})$ at $287.6 \mathrm{eV}$ and carboxyl groups $(\mathrm{O}-\mathrm{C}=\mathrm{O})$ at $288.6 \mathrm{eV}$, respectively. It was noted that, a new peak at $283.3 \mathrm{eV}$ arose in $C 1 s$ spectrum of $\mathrm{C}_{60}-\mathrm{Fe}$, which was considered to be the characteristic peak of $\mathrm{C}-\mathrm{Fe}$ $[29,30]$, showing the direct attachment of Fe to carbon framework. Also, the interaction between $\mathrm{Fe}$ compounds and $\mathrm{C}_{60}$ made the peak of $\mathrm{C}=\mathrm{C} / \mathrm{C}-\mathrm{C}$ and $\mathrm{C}-\mathrm{O}$ greatly shifted to lower binding energy. Moreover, in the O1s spectrum of $\mathrm{C}_{60}$, the only peak of hydroxyl group $(-\mathrm{OH})$ at $531.6 \mathrm{eV}$ was observed. While for $\mathrm{C}_{60}-\mathrm{Fe}$, the peak of $-\mathrm{OH}$ at $531.5 \mathrm{eV}, \mathrm{C}-\mathrm{O}$ at $534.4 \mathrm{eV}, \mathrm{C}-\mathrm{OH} / \mathrm{C}-\mathrm{O}-\mathrm{C}$ at $532.8 \mathrm{eV}, \mathrm{Fe}-\mathrm{O}$ at $530.7 \mathrm{eV}$ and oxide at $529.6 \mathrm{eV}$ all could be easily found. Combined the Fe characterization in XPS and $\mathrm{XRD}$, it was found that the valence of $\mathrm{Fe}$ was changed and there were both divalent and trivalent irons in $\mathrm{C}_{60}-\mathrm{Fe} . \mathrm{C}_{60}$ are very difficult to be oxidized except in presence of proton acid [31,32], therefore, the obvious increase of oxygen content in $\mathrm{C}_{60}-\mathrm{Fe}$ should not be due to the oxidation of carbon on $\mathrm{C}_{60}$ framework. While there was a very small amount of carbon-heteroatom bonds $(\mathrm{C}-\mathrm{O}, \mathrm{C}=\mathrm{O}, \mathrm{O}-\mathrm{C}=\mathrm{O}, \mathrm{OH}$, etc.) in $\mathrm{C}_{60}$, which could be involved in the reaction with oxygen in $\mathrm{C}_{60}-\mathrm{Fe}$ synthetic reaction. Of course, most oxygen was introduced into the structure of $\mathrm{C}_{60}-\mathrm{Fe}$ through an oxidation-reduction reaction with $\mathrm{Fe}$, resulting in the appearance of $\mathrm{Fe}-\mathrm{O}$ bonds and oxides $\left(\mathrm{FeO}, \mathrm{Fe}_{2} \mathrm{O}_{3}\right.$ and $\left.\mathrm{Fe}_{3} \mathrm{O}_{4}\right)$ in $\mathrm{C}_{60}$ - $\mathrm{Fe}$.

\subsection{Dispersion of $\mathbf{C}_{60}-\mathbf{F e}$}

The dispersion of $\mathrm{C}_{60}$ and $\mathrm{C}_{60}$-Fe in $\mathrm{PE}$ was shown in Figure 2. In order to better observe the dispersion of nanofillers, IFR was not added and the content of $\mathrm{C}_{60}$ and $\mathrm{C}_{60}-\mathrm{Fe}$ was $5 \mathrm{wt} \%$. It can be observed that $\mathrm{C}_{60}$ were easily agglomerated in matrix, and the size of agglomerates could reach several hundred nanometers. Meanwhile, the size of $\mathrm{C}_{60}-\mathrm{Fe}$ in matrix was much smaller and the dispersion was more uniform.

\subsection{Flame behaviors}

The parameters tested in a cone calorimetric measurement, including the peak of heat release rate $(P H R R)$, the total heat released $(T H R)$, ignition time (tign) and time to PHRR ( $\left.t_{\mathrm{PHRR}}\right)$, were shown in Table 2 and the heat release rate curves of PE composites in Figure 3. PE/15IFR was very easy to be ignited ( $t_{\text {ign }}$ was $\left.67 \mathrm{~s}\right)$ and would burn violently once ignited (as shown in Figure $3 \mathrm{~b}$ ). The $t_{\text {ign }}$ was slightly prolonged when $2 \mathrm{wt} \%$ IFR was substituted by $\mathrm{C}_{60}$ (due to the free radical scavenging effect of $\mathrm{C}_{60}$, which was proved by ESR [15]), the peak of heat release rate and the total heat released both increased. When IFR was replaced by lower content $\mathrm{C}_{60} \mathrm{Fe}$ $\left(\mathrm{PE} / 14 \mathrm{IFR} / 1 \mathrm{C}_{60}-\mathrm{Fe}\right), t_{\text {ign }}(101 \mathrm{~s})$ and $t_{\mathrm{PHRR}}(374 \mathrm{~s})$ were prolonged dramatically, PHRR and THR decreased slightly. When $2 \mathrm{wt} \% \mathrm{C}_{60}$-Fe was added $\left(\mathrm{PE} / 13 \mathrm{IFR} / 2 \mathrm{C}_{60}-\mathrm{Fe}\right)$, the ignition time and time to PHRR was increased by 70 and $119 \%$ compared with PE/15IFR, respectively. Meanwhile, PHRR was sharply dropped to $380 \mathrm{~kW} / \mathrm{m}^{2}$. With further increase of $\mathrm{C}_{60}-\mathrm{Fe}\left(\mathrm{PE} / 12 \mathrm{IFR} / 3 \mathrm{C}_{60}-\mathrm{Fe}\right)$, the ignition time was prolonged while $P H R R$ increased remarkably.

The morphologies and Raman spectra of char obtained after cone test were presented in Figure 4 and Figure 5. There were many holes on the char surface of PE/15IFR which could not provide a barrier to resist the transfer of the heat, combustible gases and free radicals. Similar morphology could be seen for $\mathrm{PE} / 13 \mathrm{IFR} / 2 \mathrm{C}_{60}$. When IFR and $\mathrm{C}_{60}$-Fe were combined, a continuous, smooth and compact surface was formed. Raman spectroscopy is performed to characterize the graphitization degree of carbon materials. $I_{\mathrm{D}} / I_{\mathrm{G}}$ is the relevant intensity ratio of $D$ and $G$ bands, which is regarded as an efficient measure to evaluate the disorder degree of carbon materials 

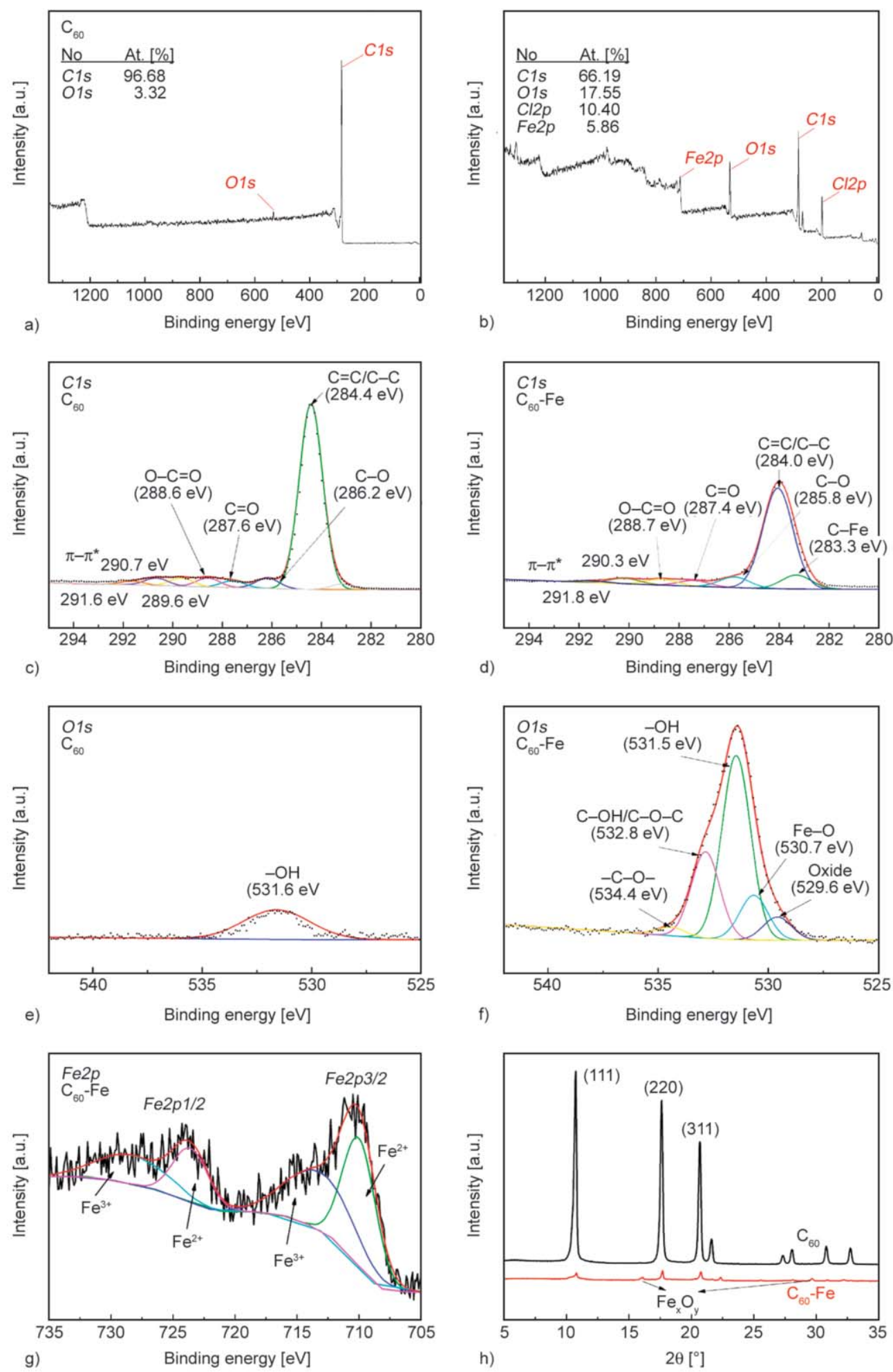

Figure 1. XPS and XRD spectra of $\mathrm{C}_{60}$ and $\mathrm{C}_{60}$-Fe. a) XPS survey spectrum of $\mathrm{C}_{60}$; b) XPS survey spectrum of $\mathrm{C}_{60}-\mathrm{Fe}$; c) XPS $C 1 s$ spectrum of $\mathrm{C}_{60}$; d) XPS $C 1 s$ spectrum of $\mathrm{C}_{60}-\mathrm{Fe} ;$ e) XPS $O 1 s$ spectrum of $\mathrm{C}_{60}$; f) XPS O1s spectrum of $\mathrm{C}_{60}-\mathrm{Fe}$; g) XPS $\mathrm{Fe} 2 p$ spectrum of $\mathrm{C}_{60}-\mathrm{Fe}$; h) XRD spectrum of $\mathrm{C}_{60}-\mathrm{Fe}$.

[33]. Compared with PE/15IFR, the $I_{\mathrm{D}} / I_{\mathrm{G}}$ value was decreased because of the addition of $\mathrm{C}_{60}$-Fe suggesting the enhancement of the graphitization degree of char of $\mathrm{PE} / 13 \mathrm{IFR} / 2 \mathrm{C}_{60}-\mathrm{Fe}$.

\subsection{Mechanism}

A simple flame retardant mechanism of PE/IFR, $\mathrm{PE} / \mathrm{IFR} / \mathrm{C}_{60}$ and $\mathrm{PE} / \mathrm{IFR} / \mathrm{C}_{60}-\mathrm{Fe}$ composites was presented in Figure 6. For PE/IFR composites, IFR 


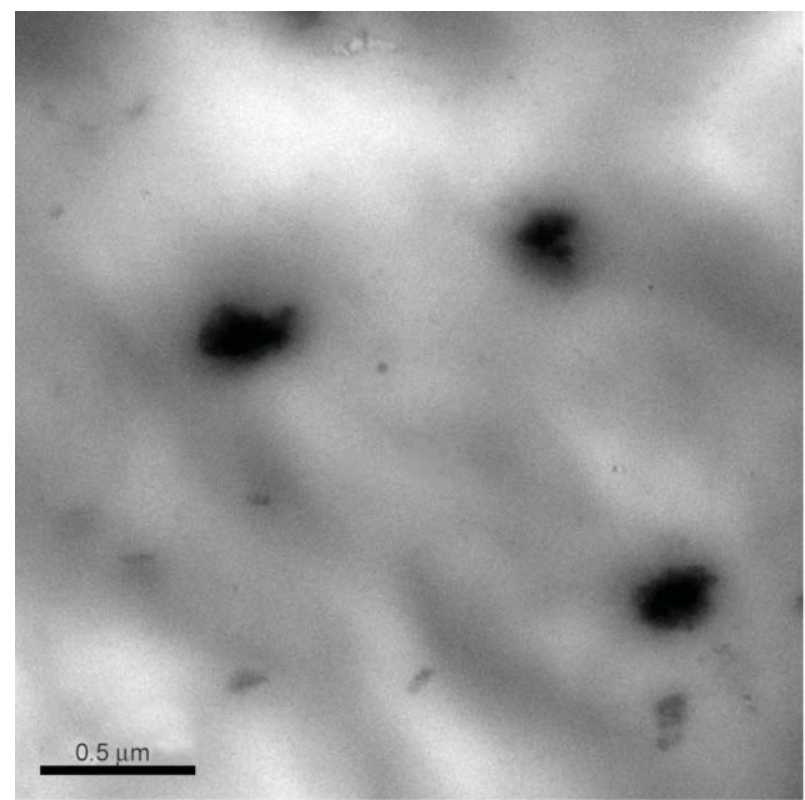

a)

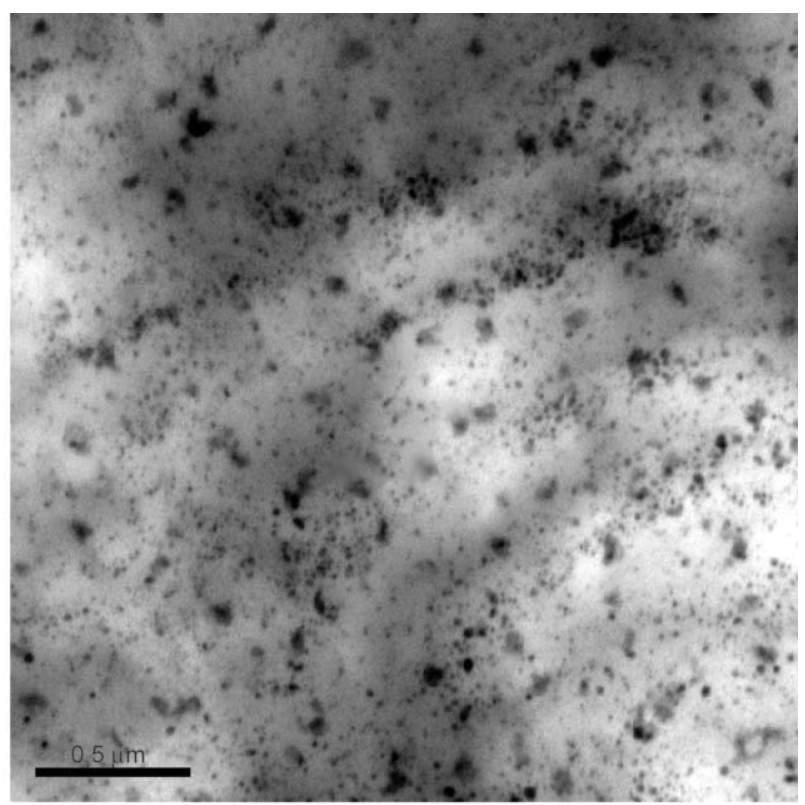

b)

Figure 2. The dispersion of $\mathrm{C}_{60}$ and $\mathrm{C}_{60}$-Fe in PE. a) $\mathrm{PE} / 5 \mathrm{C}_{60}$; b) $\mathrm{PE} / 5 \mathrm{C}_{60}-\mathrm{Fe}$.

Table 2. The cone calorimetry data of PE composites ${ }^{\mathrm{a}}$.

\begin{tabular}{|c|c|c|c|c|}
\hline Sample code & $\begin{array}{l}t_{\text {ign }} \\
{[\mathrm{s}]}\end{array}$ & $\begin{array}{c}\text { PHRR } \\
{\left[\mathrm{kW} / \mathrm{m}^{2}\right]}\end{array}$ & $\begin{array}{c}t_{\mathrm{PHRR}} \\
{[\mathrm{s}]}\end{array}$ & $\begin{array}{c}\text { THR } \\
{\left[\mathrm{MJ} / \mathrm{m}^{2}\right]}\end{array}$ \\
\hline PE/15IFR & 67 & 547 & 208 & 92.3 \\
\hline $\mathrm{PE} / 14 \mathrm{IFR} / 1 \mathrm{C}_{60}-\mathrm{Fe}$ & $\begin{array}{c}101 \\
(+51 \%)\end{array}$ & $\begin{array}{l}518 \\
(-5 \%)\end{array}$ & $\begin{array}{c}374 \\
(+80 \%)\end{array}$ & $\begin{array}{c}90.7 \\
(-2 \%)\end{array}$ \\
\hline $\mathrm{PE} / 13 \mathrm{IFR} / 2 \mathrm{C}_{60}-\mathrm{Fe}$ & $\begin{array}{c}114 \\
(+70 \%)\end{array}$ & $\begin{array}{c}380 \\
(-31 \%)\end{array}$ & $\begin{array}{c}455 \\
(+119 \%)\end{array}$ & $\begin{array}{c}85.4 \\
(-7 \%)\end{array}$ \\
\hline $\mathrm{PE} / 12 \mathrm{IFR} / 3 \mathrm{C}_{60}-\mathrm{Fe}$ & $\begin{array}{c}126 \\
(+88 \%)\end{array}$ & $\begin{array}{c}773 \\
(+41 \%)\end{array}$ & $\begin{array}{c}445 \\
(+114 \%)\end{array}$ & $\begin{array}{c}91.5 \\
(-1 \%)\end{array}$ \\
\hline $\mathrm{PE} / 13 \mathrm{IFR} / 2 \mathrm{C}_{60}$ & $\begin{array}{c}72 \\
(+7 \%)\end{array}$ & $\begin{array}{l}582 \\
(+6 \%)\end{array}$ & $\begin{array}{c}208 \\
(-)\end{array}$ & $\begin{array}{c}98.6 \\
(+7 \%)\end{array}$ \\
\hline
\end{tabular}

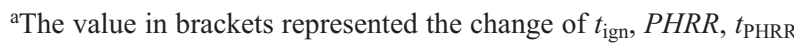
and $T H R$ of $\mathrm{PE} / \mathrm{IFR} / \mathrm{C}_{60}-\mathrm{Fe}$ relative to PE/IFR which had the same total content of flame retardant additive. decomposed forming a char layer during thermal degradation or ignition. However, underfed IFR in $\mathrm{PE}$ was not enough to form a dense and continuous char layer during thermal degradation or combustion. Loose structures, broken carbon layers and even some big holes all acted as the pathway of evolved volatiles and heat. When $\mathrm{C}_{60}$ was added in PE/IFR composite, $\mathrm{C}_{60}$ has the excellent trappingradicals ability to capture free radicals formed during thermal decomposition of polymer, which delayed the combustion process, $t_{\text {ign }}$ was prolonged. However, the addition of $\mathrm{C}_{60}$ had little effects on the char layers formed by the decomposition of IFR, the heat
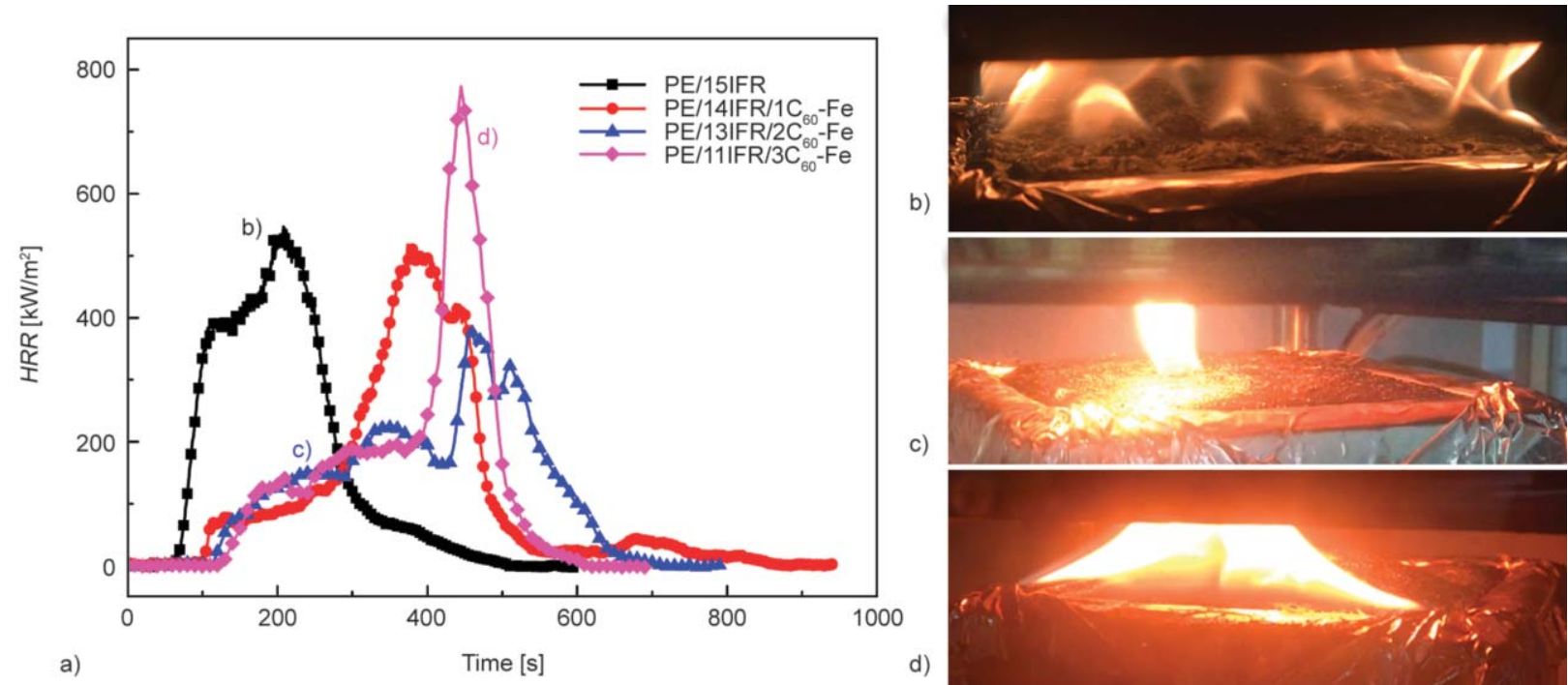

c)

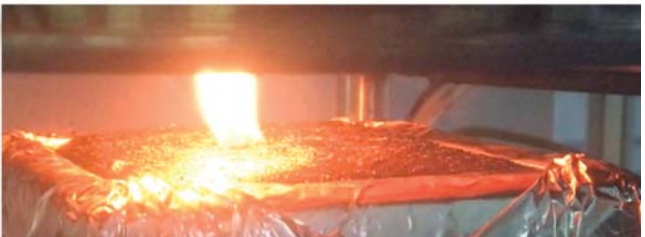

d)

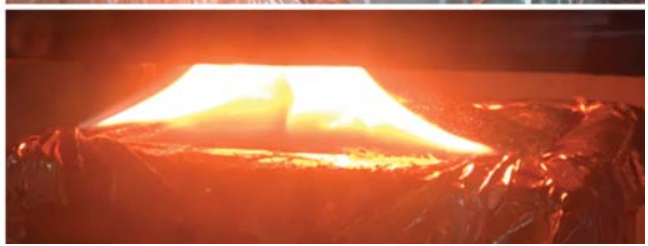

Figure 3. Flame behaviors of PE composites. a) Heat release rate curves of PE composites; b) digital photograph of burning process of PE/15IFR; c) digital photograph of burning process of $\mathrm{PE} / 13 \mathrm{IFR} / 2 \mathrm{C}_{60}$-Fe; d) digital photograph of burning process of $\mathrm{PE} / 13 \mathrm{IFR} / 2 \mathrm{C}_{60}$. 

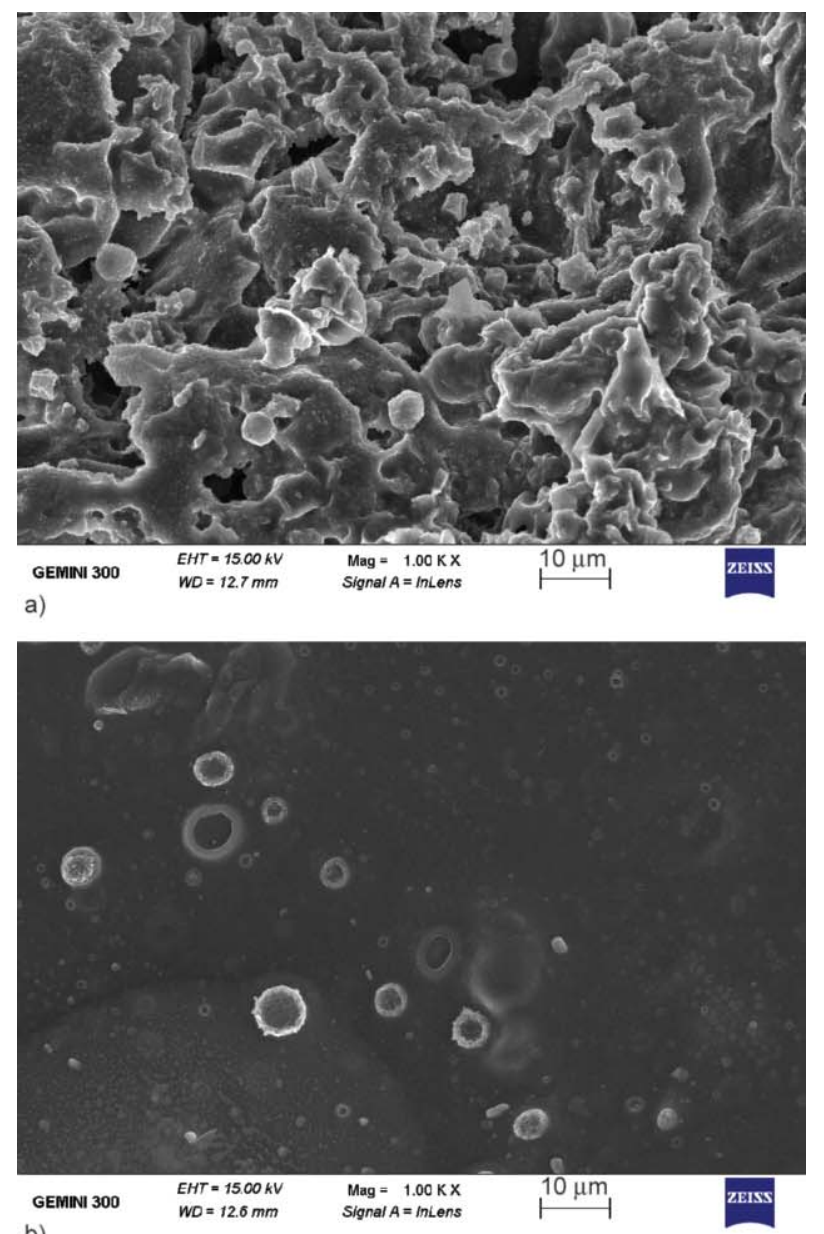

b)

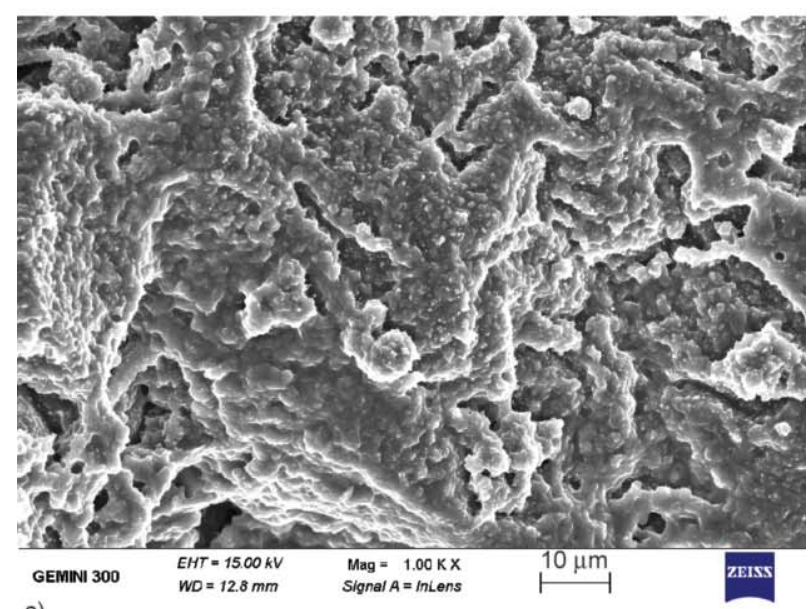

c)

Figure 4. SEM images of the char. a) PE/15IFR; b) PE/ $13 \mathrm{IFR} / 2 \mathrm{C}_{60}-\mathrm{Fe}$; c) $\mathrm{PE} / 13 \mathrm{IFR} / 2 \mathrm{C}_{60}$.

release could not be relieved. When partial IFR was replaced by $\mathrm{C}_{60}-\mathrm{Fe}$, the $\mathrm{C}_{60}$-Fe could also capture the free radicals generated by degradation of $\mathrm{PE}$, remarkably prolonging the $t_{\text {ign }}$ and $t_{\mathrm{PHRR}}$. Moreover, a complete char barrier would be formed on the surface of matrix due to the catalytic charring ability of $\mathrm{Fe}$, which could slow down the heat release. Compared with the flame of PE/15IFR, the flame of PE/13IFR/
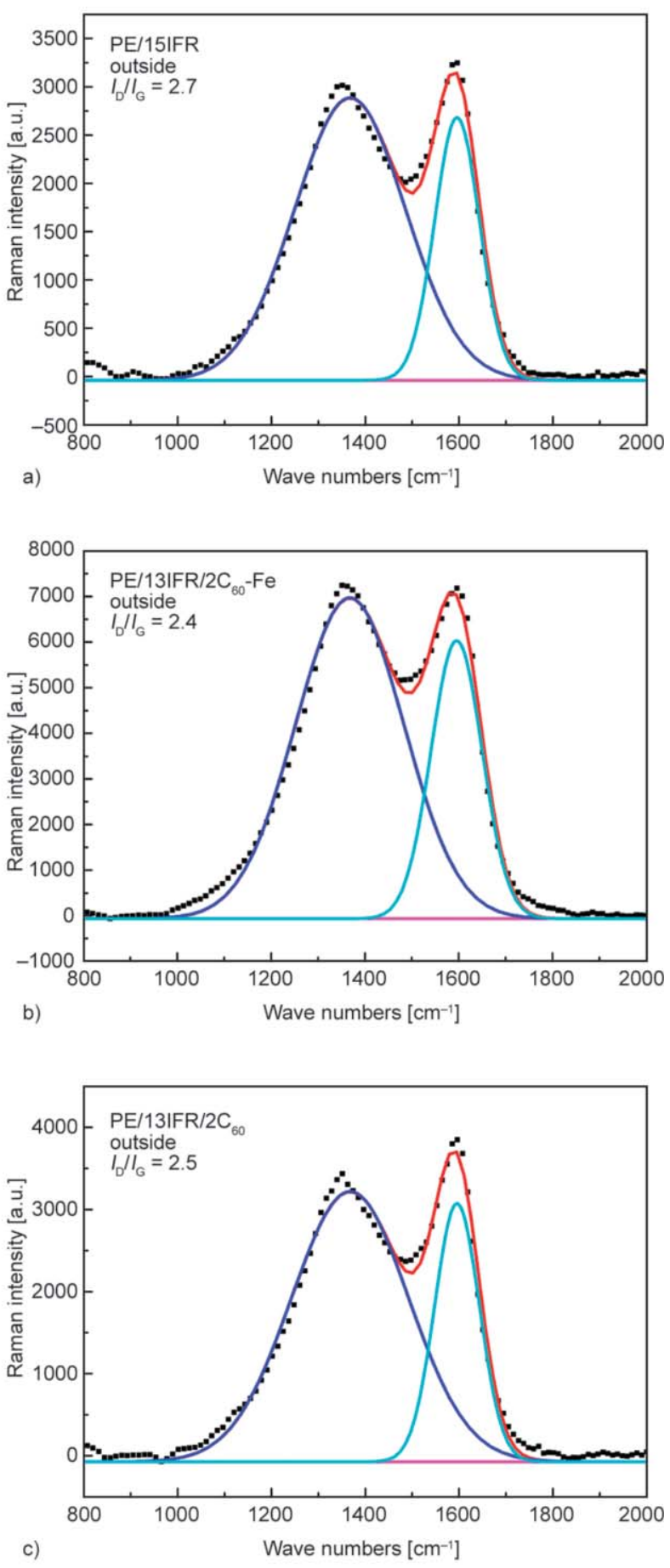

Figure 5. Raman spectra of the char. a) PE/15IFR; b) PE/ $13 \mathrm{IFR} / 2 \mathrm{C}_{60}-\mathrm{Fe}$; c) $\mathrm{PE} / 13 \mathrm{IFR} / 2 \mathrm{C}_{60}$.

$2 \mathrm{C}_{60^{-}} \mathrm{Fe}$ was much smaller. When the content of $\mathrm{C}_{60^{-}}$ $\mathrm{Fe}$ was exceeded, the char layer became thinner and was easy to be destroyed due to the low content of IFR. Otherwise, once the char layer broke, a large number of combustible substances would escape into gas resulting in the sharply increase of $P H R R$. In other words, the right content of $\mathrm{C}_{60}$-Fe could promote the formation of better char layer, which could 


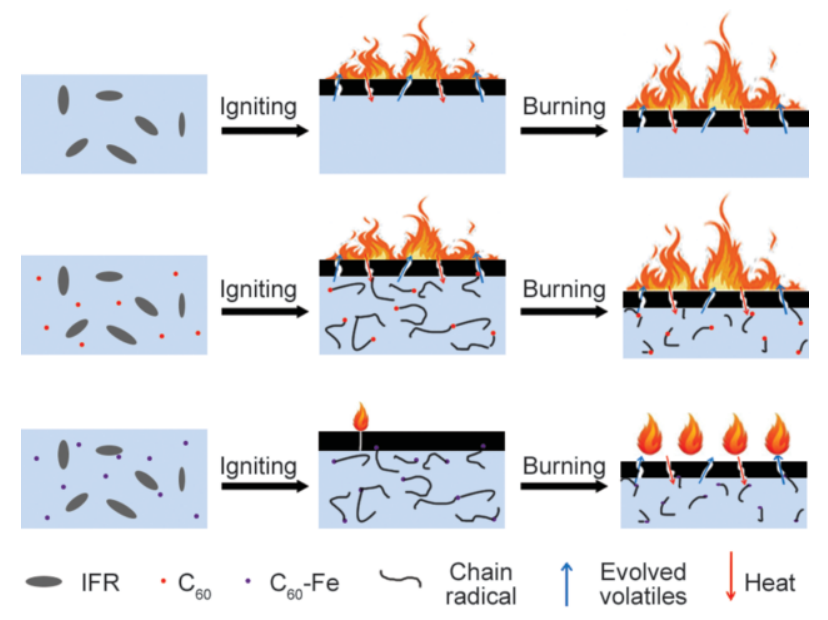

Figure 6. Proposed mechanism for flame retardant.

protect the matrix at the beginning of combustion and was not easily destroyed, showing better flame retardant properties.

\section{Conclusions}

$\mathrm{C}_{60}$ - $\mathrm{Fe}$ was synthesized formC $\mathrm{C}_{60}$ and $\mathrm{FeCl}_{3} \cdot 6 \mathrm{H}_{2} \mathrm{O}$ via a solution reaction. In the process of synthesis, part of $\mathrm{Fe}^{3}+$ was reduced to $\mathrm{Fe}^{2+}$ and many oxygencontaining structures were introduction to $\mathrm{C}_{60}$. $\mathrm{C}_{60^{-}}$ $\mathrm{Fe}$ was combined with intumescent flame retardant to prepare flame retardant polyethylene. When replacing $2 \mathrm{wt} \%$ IFR with $\mathrm{C}_{60}-\mathrm{Fe}$, the flame retardant properties of PE/IFR composites enhanced remarkably. The catalytic charring ability of Fe increase the graphitization degree of char residues and helped to form an more compact and continuous char layer, causing the heat release were reduced and PHRR/ THR were reduced from $547 / 92.3$ to $380 / 85.4 \mathrm{MJ} / \mathrm{m}^{2}$, respectively. Meanwhile, the radical trapping effect of $\mathrm{C}_{60}$ blocked the degradation process of $\mathrm{PE}$, and the $t_{\text {ign }} / t_{\text {PHRR }}$ were prolonged from $67 / 208$ to $114 / 455 \mathrm{~s}$, respectively. $\mathrm{C}_{60}-\mathrm{Fe}$ made the radicalscavenging mechanism of $\mathrm{C}_{60}$ and condensed-phase mechanism of IFR integrated better.

\section{Acknowledgements}

This work was supported by the National Natural Science Foundations of China (No. 51703197, 51673173), the Ningbo Science and Technology Innovation Team (No. 2015B11005) and the Natural Science Foundations of Ningbo (No. 2018A610102).

\section{References}

[1] Ran S., Zhao L., Han L., Guo Z., Fang Z.: Improvement of the thermal and thermo-oxidative stability of highdensity polyethylene by free radical trapping of rare earth compound. Themochimica Acta, 612, 55-62 (2015). https://doi.org/10.1016/j.tca.2015.05.006

[2] Yang W., Tang G., Song L., Hu Y., Yuan R. K. K.: Effect of rare earth hypophosphite and melamine cyanurate on fire performance of glass-fiber reinforced poly $(1,4-$ butylene terephthalate) composites. Thermochimica Acta, 526, 185-191 (2011). https://doi.org/10.1016/j.tca.2011.09.022

[3] Zhang Z., Xu W., Yuan L., Guan Q., Liang G., Gu A.: Flame-retardant cyanate ester resin with suppressed toxic volatiles based on environmentally friendly halloysite nanotube/graphene oxide hybrid. Journal of Applied Polymer Science, 135, 46587/1-46587/13 (2018). https://doi.org/10.1002/app.46587

[4] Xie H., Lai X., Zhou R., Li H., Zhang Y., Zeng X., Guo J.: Effect and mechanism of $N$-alkoxy hindered amine on the flame retardancy, UV aging resistance and thermal degradation of intumescent flame retardant polypropylene. Polymer Degradation and Stability, 118, 167177 (2015).

https://doi.org/10.1016/j.polymdegradstab.2015.04.022

[5] Xie H., Lai X., Li H., Zeng X.: Remarkably improving the fire-safety of polypropylene by synergism of functionalized $\mathrm{ZrP}$ nanosheet and $\mathrm{N}$-alkoxy hindered amine. Applied Clay Science, 166, 61-73 (2018).

https://doi.org/10.1016/j.clay.2018.09.004

[6] Xie H., Lai X., Li H., Zeng X.: Synthesis of a novel macromolecular charring agent with free-radical quenching capability and its synergism in flame retardant polypropylene. Polymer Degradation and Stability, 130, 6877 (2016).

https://doi.org/10.1016/j.polymdegradstab.2016.05.029

[7] Fang Z., Song P., Tong L., Guo Z.: Thermal degradation and flame retardancy of polypropylene $/ \mathrm{C}_{60}$ nanocomposites. Thermochimica Acta, 473, 106-108 (2008). https://doi.org/10.1016/j.tca.2008.04.019

[8] Song P., Zhu Y., Tong L., Fang Z.: C(60) reduces the flammability of polypropylene nanocomposites by in situ forming a gelled-ball network. Nanotechnology, 19, 225707/1-225707/10 (2008).

https://doi.org/10.1088/0957-4484/19/22/225707

[9] Zhao L., Song P., Cao Z., Fang Z., Guo Z.: Thermal stability and rheological behaviors of high-density polyethylene/fullerene nanocomposites. Journal of Nanomaterials, 2012, 340962/1-340962/6 (2012). https://doi.org/10.1155/2012/340962

[10] Zhao L., Guo Z., Cao Z., Zhang T., Fang Z., Peng M.: Thermal and thermo-oxidative degradation of high density polyethylene/fullerene composites. Polymer Degradation and Stability, 98, 1953-1962 (2013). https://doi.org/10.1016/j.polymdegradstab.2013.07.020 
[11] Zhao L., Cao Z., Fang Z., Guo Z.: Influence of fullerene on the kinetics of thermal and thermo-oxidative degradation of high-density polyethylene by capturing free radicals. Journal of Thermal Analysis and Calorimetry, 114, 1287-1294 (2013). https://doi.org/10.1007/s10973-013-3158-4

[12] Zhao L., Guo Z., Ran S., Cao Z., Fang Z.: The effect of fullerene on the resistance to thermal degradation of polymers with different degradation processes. Journal of Thermal Analysis and Calorimetry, 115, 1235-1244 (2014). https://doi.org/10.1007/s10973-013-3453-0

[13] Guo Z., Zhao L., Fang Z.: The flame retardant and smoke suppression effect of fullerene by trapping radicals in decabromodiphenyl oxide $/ \mathrm{Sb}_{2} \mathrm{O}_{3}$ flame-retarded high density polyethylene. Fire and Materials, 41, 916-924 (2017). https://doi.org/10.1002/fam.2433

[14] Zhou X., Ran S., Hu H., Fang Z.: Improving flame-retardant efficiency by incorporation of fullerene in styrene-butadiene-styrene block copolymer/aluminum hydroxide composites. Journal of Thermal Analysis and Calorimetry, 125, 199-204 (2016).

https://doi.org/10.1007/s10973-016-5354-5

[15] Pan Y., Han L., Guo Z., Fang Z.: Improving the flameretardant efficiency of aluminum hydroxide with fullerene for high-density polyethylene. Journal of Applied Polymer Science, 134, 44551/1-44551/9 (2016). https://doi.org/10.1002/app.44551

[16] Salikhov T. K., Tabarov S. K., Rashidov D., Tuichiev S., Hussein A.: Effect of $\mathrm{C}_{60}$ fullerene additions on the thermal conductivity of low-density polyethylene films. Technical Physics, 56, 570-572 (2011). https://doi.org/10.1134/s106378421104027x

[17] Wu N., Yang R., Hao J., Liu G.: Synergistic effect of metal oxides on intumescent flame-retardant PP systems. Acta Polymerica Sinica, 12, 1205-1210 (2009). https://doi.org/10.3724/SP.J.1105.2009.01205

[18] Lam Y. L., Kan C. W., Yuen C. W. M.: Objective measurement of hand properties of plasma pre-treated cotton fabrics subjected to flame-retardant finishing catalyzed by zinc oxide. Fibers and Polymers, 15, 1880-1886 (2014). https://doi.org/10.1007/s12221-014-1880-6

[19] Lam Y. L., Kan C. W., Yuen C. W. M.: Effect of oxygen plasma pretreatment and titanium dioxide overlay coating on flame retardant finished cotton fabrics. Bioresources, 6, 1454-1474 (2011).

[20] Hong N., Song L., Hull T. R., Stec A. A., Wang B., Pan Y., Hu Y.: Facile preparation of graphene supported $\mathrm{Co}_{3} \mathrm{O}_{4}$ and $\mathrm{NiO}$ for reducing fire hazards of polyamide 6 composites. Materials Chemistry and Physics, 142, 531-538 (2013).

https://doi.org/10.1016/j.matchemphys.2013.07.048
[21] Jang J., Kim J., Bae J. Y.: Effects of lewis acid-type transition metal chloride additives on the thermal degradation of ABS. Polymer Degradation and Stability, 88, 324-332 (2005). https://doi.org/10.1016/j.polymdegradstab.2004.11.008

[22] Zhang Y., Li X., Fang Z., Hull T. R., Kelarakis A., Stec A. A.: Mechanism of enhancement of intumescent fire retardancy by metal acetates in polypropylene. Polymer Degradation and Stability, 136, 139-145 (2017). https://doi.org/10.1016/j.polymdegradstab.2016.12.018

[23] Wang J-S., Liu Y., Zhao H-B., Liu J., Wang D-Y., Song Y-P., Wang Y-Z.: Metal compound-enhanced flame retardancy of intumescent epoxy resins containing ammonium polyphosphate. Polymer Degradation and Stability, 94, 625-631 (2009).

https://doi.org/10.1016/j.polymdegradstab.2009.01.006

[24] Wang L., Yang W., Wang B., Wu Y., Hu Y., Song L., Yuen R. K. K.: The impact of metal oxides on the combustion behavior of ethylene-vinyl acetate coploymers containing an intumenscent flame retardant. Industrial and Engineering Chemistry Research, 51, 7884-7890 (2012).

https://doi.org/10.1021/ie202502s

[25] Liu L., Chen X., Jiao C.: Influence of ferric phosphate on smoke suppression properties and combustion behavior of intumescent flame retardant epoxy composites. Iranian Polymer Journal, 24, 337-347 (2015). https://doi.org/10.1007/s13726-015-0327-2

[26] Liu L., Zhuo J., Chen X., Jiao C., Li S., Gu Y.: Influence of ferric hydroxide on smoke suppression properties and combustion behavior of intumescent flame retardant silicone rubber composites. Journal of Thermal Analysis and Calorimetry, 119, 487-497 (2015). https://doi.org/10.1007/s10973-014-4108-5

[27] Chen X., Li M., Zhuo J., Ma C., Jiao C.: Influence of $\mathrm{Fe}_{2} \mathrm{O}_{3}$ on smoke suppression and thermal degradation properties in intumescent flame-retardant silicone rubber. Journal of Thermal Analysis and Calorimetry, 123, 439-448 (2016). https://doi.org/10.1007/s10973-015-4911-7

[28] Cai Y., Huang F., Wei Q., Song L., Hu Y., Ye Y., Xu Y., Gao W.: Structure, morphology, thermal stability and carbonization mechanism studies of electrospun PA6/ Fe-OMT nanocomposite fibers. Polymer Degradation and Stability, 93, 2180-2185 (2008). https://doi.org/10.1016/j.polymdegradstab.2008.08.003

[29] Liu X., Jiang H., Ye J., Zhao C., Gao S., Wu C., Li C., Li J., Wang X.: Nitrogen-doped carbon quantum dot stabilized magnetic iron oxide nanoprobe for fluorescence, magnetic resonance, and computed tomography triple-modal in vivo bioimaging. Advanced Functional Materials, 26, 8694-8706 (2016). https://doi.org/10.1002/adfm.201603084

[30] Chen W., Yan B.: The synthesis and absorption spectrum of $\left.\left[\mathrm{Fe}\left(\mathrm{C}_{60}\right)\right] \cdot \mathrm{ClO}\right]$. Spectroscopy and Spectral Analysis, 19, 529-530 (1999). 
[31] Fagan P. F., Calabrese J. C., Malone B.: The chemical nature of buckminsterfullerene $\left(\mathrm{C}_{60}\right)$ and the characterization of a platinum derivative. Science, 252, 1160 1161 (1991).

https://doi.org/10.1002/chin.199137032

[32] Ostrovskaya L. Y.: Characterization of different carbon nanomaterials promising for biomedical and sensor applications by the wetting method. Powder Metallurgy and Metal Ceramics, 42, 1-8 (2003).

https://doi.org/10.1023/a:1023978613302
[33] Fang F., Song P., Ran S., Guo Z., Wang H., Fang Z.: A facile way to prepare phosphorus-nitrogen-functionalized graphene oxide for enhancing the flame retardancy of epoxy resin. Composites Communications, 10, 97102 (2018).

https://doi.org/10.1016/j.coco.2018.08.001 